\title{
Lars Klöhn
}

\section{Das System der aktien- und umwandlungsrechtlichen Abfindungsansprüche}

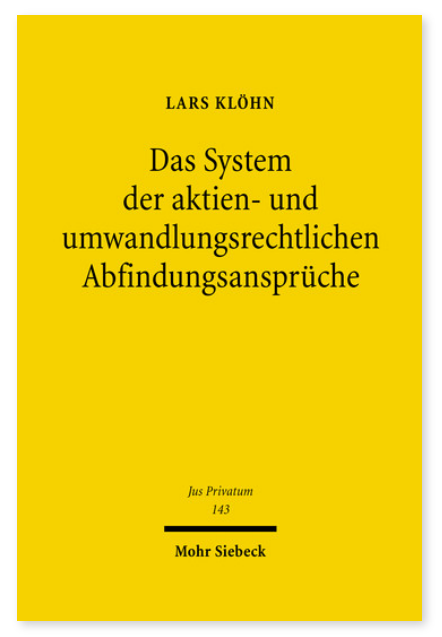

2009. XXV, 478 Seiten. JusPriv 143

ISBN 978-3-16-151220-9

DOI 10.1628/978-3-16-151220-9

eBook PDF 134,00€

ISBN 978-3-16-150033-6

Leinen $134,00 €$
In der Aktiengesellschaft dürfen Mehrheitsaktionäre Entscheidungen gegen den Willen der übrigen Anteilsinhaber fällen (Mehrheitsprinzip). Dies gilt grundsätzlich auch dann, wenn hiermit tiefe Eingriffe in die Mitgliedschaft der

Minderheitsaktionäre verbunden sind. Bisweilen müssen die Minderheitsaktionäre diese Entscheidungen hinnehmen, in anderen Fällen können sie gegen Abfindung aus der Gesellschaft austreten (§§ 305, 320b, 327a AktG, 29, 122i, 207 UmwG, §§ 7, 9, 12 SEAG, § 39a WpÜG). Lars Klöhn unternimmt den Versuch, das innere System des durch diese Normen abgesteckten Rechtsgebiets herauszuarbeiten, um hierdurch seine wertungsmäßige Folgerichtigkeit und Einheit zu verwirklichen. Dabei bleibt der Blick nicht auf die Wertungen des einfachen Rechts beschränkt, sondern erfasst auch seine europa- und verfassungsrechtlichen sowie rechtsökonomischen Grundlagen.

Lars Klöhn Geboren 1976; Studium der Rechtswissenschaft in Göttingen und Cambridge (USA); derzeit Professor für Bürgerliches Recht, Handels- und Wirtschaftsrecht sowie Rechtsvergleichung an der Philipps-Universität Marburg.
Jetzt bestellen:

https://mohrsiebeck.com/buch/das-system-der-aktien-und-umwandlungsrechtlichen-abfindungsansprueche9783161512209?no_cache=1

order@mohrsiebeck.com

Telefon: +49 (0)7071-923-17

Telefax: $+49(0) 7071-51104$ 